\title{
SHORT COMMUNICATION \\ Novas ocorrências e descrição da fêmea de Pero minetraria (Oberthür) (Lepidoptera: Geometridae)
}

\author{
Manoel Martins Dias \\ Departamento de Ecologia e Biologia Evolutiva, Universidade Federal de São Carlos. Caixa Postal 676, 13565-905 São \\ Carlos, São Paulo, Brasil. E-mail: manoelmd@power.ufscar.br
}

\begin{abstract}
New records and description of the female of Pero minetraria (Oberthür) (Lepidoptera: Geometridae). The female of Pero minetraria (Oberthür, 1912) is described for the first time and new records for the species in southeastern Brazil are added. The female has filiform antennae and brownish ground colour; outer margin of forewing more dentate comparing to male.
\end{abstract}

KEY WORDS. Ennominae; female genitalia; morphology.

RESUMO. A fêmea de Pero minetraria (Oberthür, 1912) é descrita e novos registros da espécie no sudeste do Brasil são relatados. A fêmea tem antenas filiformes e coloração geral acastanhada; margem externa da asa anterior mais fortemente denteada que aquela do macho.

PALAVRAS-CHAVE. Ennominae; genitália da fêmea; morfologia.

Pero Herrich-Schäffer, 1855, gênero exclusivo do novo mundo, foi revisto por Poole (1987). Pero minetraria (Oberthür, 1912) (Geometridae: Ennominae), espécie rara em coleções, foi descrita com base em um macho de Mato Grosso, Brasil, ilustrado em ОвевтнÜr (1912, fig. 1546); o mesmo exemplar (holótipo) e a respectiva genitália foram ilustrados em Poole (1987). A fêmea, até então desconhecida, é ora descrita e comparada ao macho. Duas novas localidades de ocorrência são mencionadas, ambas no estado de São Paulo: Poloni e São Carlos.

\section{Pero minetraria (Oberthür, 1912) Figs 1-5}

Macho (Figs 1 e 2). Margem costal da asa anterior: 16 $\mathrm{mm}$. Difere da fêmea por: antenas pectinadas; prolongamentos dos artículos diminuem para o ápice da antena e são ausentes nos artículos apicais. Cabeça e tórax cinzento-acastanhados; abdome da mesma cor, com escamas castanho-escuras dispersas. Nas asas anteriores e posteriores franja castanhoacinzentada escura, também com escamas brancas apicais, entre as veias.

Asa anterior, face superior: Predomina a coloração acinzentada, com escamas castanho-escuras dispersas. Área basal cinzenta. Área mediana cinzenta, com faixa castanhoescura junto à linha pós-discal. Mácula discal branca, contornada por escamas castanho-escuras; ao redor da mácula discal e abaixo da célula discal, manchas castanho-avermelhadas. Área externa cinzenta-clara; na área esbranquiçada, junto à linha pós-discal, coloração ocrácea-clara, na qual se destacam man- chas castanho-escuras irregulares, pouco definidas e paralelas à linha pós-discal; no ápice da asa chegam até mancha castanho-escura evidente. No holótipo, duas dessas manchas (uma próxima à margem interna da asa e outra logo acima), são mais evidentes que no exemplar macho de São Carlos (Fig. 1).

Asa posterior, face superior: Branca, com escamas castanho-escuras dispersas no terço distal e junto à margem interna. Ângulo anal com coloração castanho-acinzentada, difusa, em área mais reduzida que aquela da fêmea. Não há escamas escuras ao longo das veias, como ocorre na fêmea.

Asa anterior, face inferior: Cinzento-acastanhada. Linhapós discal pouco evidente, esbranquiçada. Mácula discal branca reduzida, alongada, com algumas escamas castanho-escuras. Área externa com faixa castanho-escura pouco marcada, paralela à linha pós-discal e disposta até mancha escura próxima ao ápice da asa.

Asa posterior, face inferior: Cinzento-acastanhada, com faixa transversal castanho-escura evidente, na área externa.

Fêmea (Figs 3 e 4). Margem costal da asa anterior: $19 \mathrm{~mm}$. Palpos labiais castanhos, voltados para a frente, afilados no ápice. Vértice castanho, com algumas escamas anteriores brancas. Antenas filiformes, com artículos castanhos, recobertos totalmente na face superior por escamas brancas. Tórax e abdome castanhos. Pernas castanhas, com escamas esbranquiçadas dispersas; tarsos esbranquiçados. Nas asas anteriores e posteriores há franja castanho-escura, com escamas brancas apicais entre as veias; essa franja destaca-se, sobretudo na asa anterior, como linha escura na margem externa. 

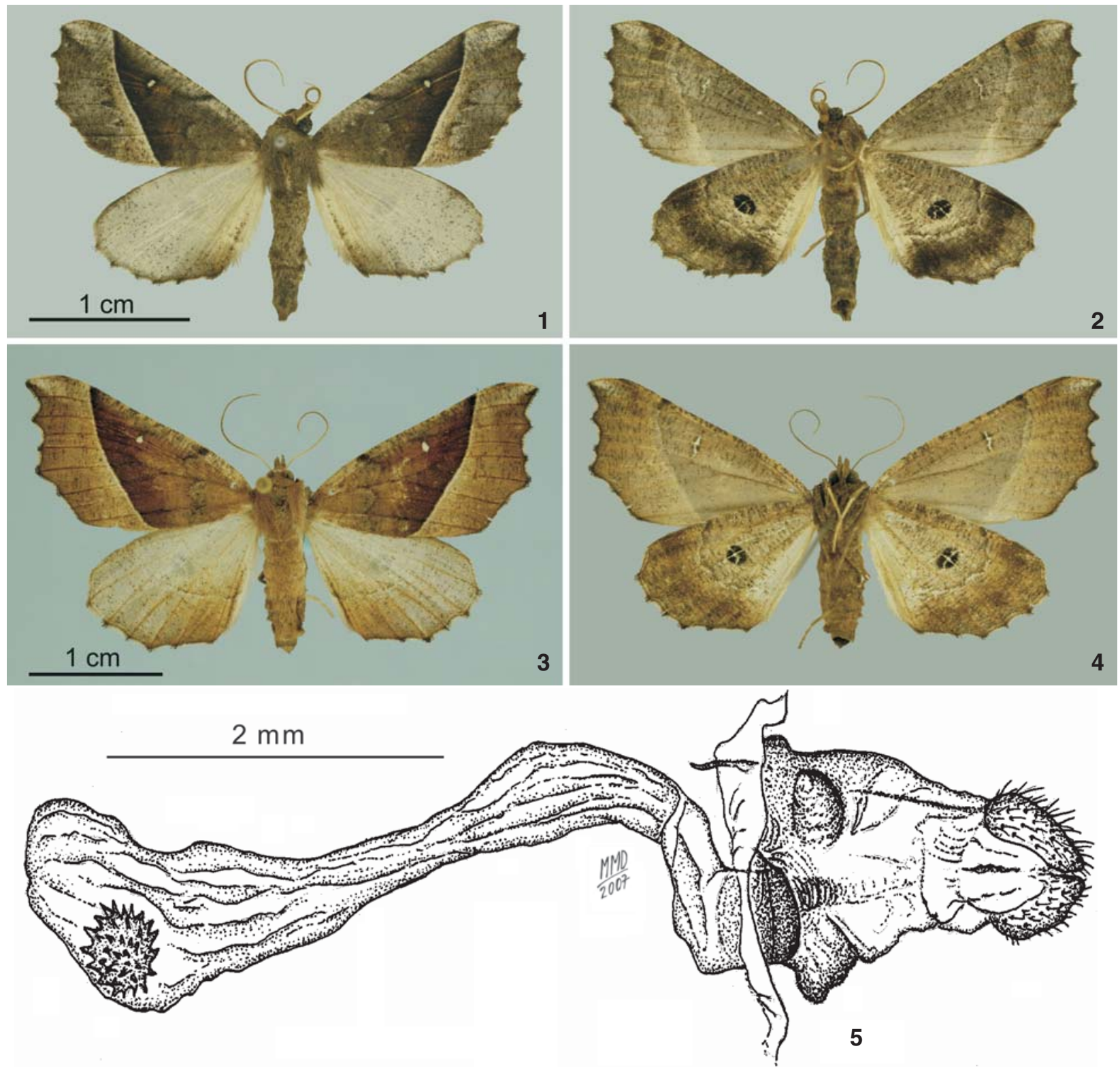

Figuras 1-5. Pero minetraria. (1-4) São Carlos, São Paulo: (1) macho, face superior; (2) macho, face inferior; (3) fêmea, face superior; (4) fêmea, face inferior; (5) Poloni, São Paulo, genitália da fêmea.

Asa anterior, face superior: área basal castanha, delimitada por linha castanha mais escura, sinuosa; coloração acinzentada junto ao lado interno dessa linha. Área mediana castanha, com faixa larga e evidente castanho-escura avermelhada, junto à linha pós-discal. Mácula discal branca, arredondada, evidente. Linha pós-discal branca, com mancha castanho-escura em seu lado interno, junto à margem costal. Da base da asa, até a linha pós-discal, margem costal acinzentada, com manchas e traços transversais castanho-escuros. Área externa castanho-clara, esbranquiçada no ápice da asa e junto à linha pós-discal; pequenos traços castanho-escuros dispersos.

Asa posterior, face superior: coloração esbranquiçada, com escamas castanho-escuras dispersas e escamas castanho-avermelhadas ao longo das veias, mais evidentes no terço distal da asa. Ângulo anal com coloração castanho-avermelhada, difusa. Linha pós-discal reduzida, visível apenas da margem interna à área central da asa.

Asa anterior, face inferior: castanha, levemente acinzen-

Revista Brasileira de Zoologia 25 (2): 373-375, June, 2008 
tada nas áreas basal e mediana. Escamas castanho-escuras dispersas ou formando pequenos traços e manchas, mais evidentes na margem costal e na área externa; nesta, há mancha esbranquiçada no ápice da asa. Área entre a margem interna e a célula discal, esbranquiçada, com escamas castanhas muito esparsas. Mácula discal alongada, branca, ladeada irregularmente por escamas castanho-escuras. Linha pós-discal pouco evidente e acinzentada, esbranquiçada do lado externo.

Asa posterior, face inferior: Castanha, com faixa transversal mais escura na área externa. Escamas castanho-escuras, dispersas. Mácula discal preta, evidente, arredondada a ovóide, com traços brancos. Linha pós-discal cinzenta ondulada, ladeada de branco externamente. Área branca ao longo da margem interna; torna-se acastanhada no ângulo anal.

Genitália (Fig. 5): papilas anais afiladas no ápice. Esterigma com lamela antevaginal esclerotizada, transversal; lamela pós-vaginal com faixa central de pequenas cristas transversais, esclerotizadas. Duto da bolsa com parte distal esclerotizada e parte proximal membranosa. Corpo da bolsa alongado, dilatado na extremidade; signo arredondado, com projeções espinescentes dispostas radialmente na superfície e nas margens.

Coleções estudadas: (BMNH) The Natural History Museum, London (M. J. Scoble); (MZSP) Museu de Zoologia da Universidade de São Paulo (C. Costa); (UFSCAR) Departamento de Ecologia e Biologia Evolutiva, Universidade Federal de
São Carlos (M.M. Dias).

Material examinado. Três machos e duas fêmeas, BrasiL, Mato Grosso: P. Germain, 1886, Ex coleção Oberthür, Brit. Mus. 1927-3, holótipo macho (BMNH). São Paulo: São Carlos, Chácara Vale Verde, 5.IV.1980, M.M. Dias leg., macho (UFSCAR); São Carlos, Fazenda Jacutinga, 8.IX.1987, U. Fernandes leg., fêmea (UFSCAR). Poloni, 30.IX.1986, F. Pinto leg., fêmea (MZSP). Examinado um exemplar de procedência incerta, com os seguintes dados: Penang, Curtis, I. 97, Ex coleção Rothschild, B.M. 1939-1, Brasil?, macho (BMNH).

\section{AGRADECIMENTOS}

Ao CNPq e à FAPESP pelos auxílios concedidos. Aos curadores das coleções mencionadas, pelo acesso ao material estudado.

\section{LITERATURA CITADA}

OвеRтнür, C. 1912. Révision des Phalénites décrites par Guenée dans le Species general des Lépidoptères (Tome IX) Famille II. Ennomidae, Guenée. Études de Lépidoptérologie comparée. 6: 223-307, 346-355.

Poole, R.W. 1987. A taxonomic revision of the new world moth genus Pero (Lepidoptera: Geometridae). United States Department of Agriculture, Technical Bulletin (1698): 1-257.

Submitted: 15.VIII.2007; Accepted: 04.VI.2008.

Editorial responsibility: Márcia Souto Couri 